\title{
COVID-19 in Hong Kong: Policies and community actions mitigate the effects of age structure and population density
}

\author{
Zilin Li $i^{1,3, \dagger}$, Stuart A. Gietel-Basten ${ }^{1,2,3,4, \dagger, *} \mathbb{D}^{\mathbb{D}}$, Rachel Ganly $^{2,3, \dagger}$ and \\ Christian Joy Pattawi Cruz ${ }^{1,3,5, \dagger}$
}

\section{Abstract}

Despite the various socio-demographic vulnerabilities of Hong Kong to the COVID19 pandemic, the city has successfully managed four waves of local outbreaks, as shown by its comparatively low numbers of confirmed cases and deaths. In this paper, we identify and differentiate the unique characteristics of Hong Kong's COVID-19 outbreaks from those of other territories, and analyse the factors that shaped these characteristics. In particular, we examine four local demographic factors - older age structure, high population density, poor housing conditions and a large migrant population - which, according to current scientific evidence, would likely indicate that the city faces a relatively high risk of the significant spread of COVID-19. We analyse and explain how multiple policies related to border controls, social distancing, testing and tracing, partial lockdowns and housing management, as well as sustained community actions, helped to mitigate the effects of these significant disadvantages.

Keywords: COVID-19; age structure; population density; policy responses; community action; Hong Kong

\footnotetext{
${ }^{1}$ Division of Public Policy, The Hong Kong University of Science and Technology, Clear Water Bay, Kowloon, Hong Kong SAR, People's Republic of China

${ }^{2}$ Division of Social Science, The Hong Kong University of Science and Technology, Clear Water Bay, Kowloon, Hong Kong SAR, People's Republic of China

${ }^{3}$ Center for Aging Science, The Hong Kong University of Science and Technology, Clear Water Bay, Kowloon, Hong Kong SAR, People's Republic of China

${ }^{4}$ Department of Humanities and Social Sciences, Khalifa University, Abu Dhabi, UAE

${ }^{5}$ Population Institute, University of the Philippines, Diliman, Quezon City, Philippines

${ }^{\dagger}$ All authors contributed equally.

${ }^{*}$ Correspondence to: Stuart A. Gietel-Basten, stuart.basten@ku.ac.ae
} 


\section{Introduction}

This paper examines and explains the extent to which demographic insights can shed light on the nature of the spread of COVID-19 in Hong Kong, Special Administrative Region of the People's Republic of China (hereafter "Hong Kong"). Hong Kong has some of the world's most densely populated neighbourhoods, and a rapidly ageing population. Based on the current scientific evidence, these factors should indicate that Hong Kong is highly vulnerable to severe outbreaks of the virus. Nonetheless, compared to the global average, the total numbers of confirmed positive cases of COVID-19 in Hong Kong have been very low. As of 28 February 2021, there had been 11,006 positive confirmed cases of COVID-19 out of a population of approximately 7.5 million people residing in an area of 1,104 square kilometres. In addition, mortality rates from COVID-19 in Hong Kong have been low relative to global averages, in terms of both population mortality and case fatality rates. We analyse and explain how, in the face of these demographic vulnerabilities, welltargeted government policies combined with community actions helped to mitigate the serious spread of the virus in Hong Kong.

Kowloon is the most densely populated area in the city and in the world, with approximately 48,930 persons per square kilometre (United Nations, Department of Economic and Social Affairs, Population Division, 2019). The "housing problem" i.e., a lack of affordable homes of reasonable quality and size - is a critical and, at times, seemingly intractable, social and policy issue in Hong Kong. By some estimates, the ratio of house prices to median wages in Hong Kong is by far the highest in the world (Cox, 2021). Hong Kong also has an ageing population, with people in the 65 and older age group comprising about one-fifth (19.1\%) of the city's total population in 2020. In addition, Hong Kong has one of the highest life expectancies in the world, at 82.9 years for males and 88.0 years for females (Census and Statistics Department, 2021).

Despite these potential vulnerabilities, Hong Kong appeared to have the first wave of the virus "under control" by late April 2020, less than three months after the first case was reported on 23 January 2020. From April to mid-July 2020, the rate of the spread of the virus was low, with the number of daily recorded positive cases of COVID-19 ranging from zero to 30 (Figure 1). In mid-July, the third wave of the pandemic began in Hong Kong. By late August 2020, the pandemic had again been brought "under control", with the number of cases declining to fewer than 20 per day. A prolonged fourth wave began in November 2020, and continued until late February 2021, when the local spread of COVID-19 appeared to have returned to low levels, with the number of new cases again falling to fewer than 20 per day.

Our research paper published in May 2020 highlighted the unique age structure of positive COVID-19 cases in the first and second waves of the outbreak in Hong Kong (Cruz et al., 2020). Despite Hong Kong's rapidly ageing population, the cases in the city were initially concentrated among the younger age groups, with the highest incidence of cases reported in the 15-24 age group. Our analysis of detailed case and travel history data highlighted the large proportions of imported cases in Hong Kong's first and second waves, and emphasised the contributions of return 
Figure 1:

Number of daily confirmed cases by transmission type and waves and seven-day averages, Hong Kong $(n=11,006,23$ January 2020 to 28 February 2021)

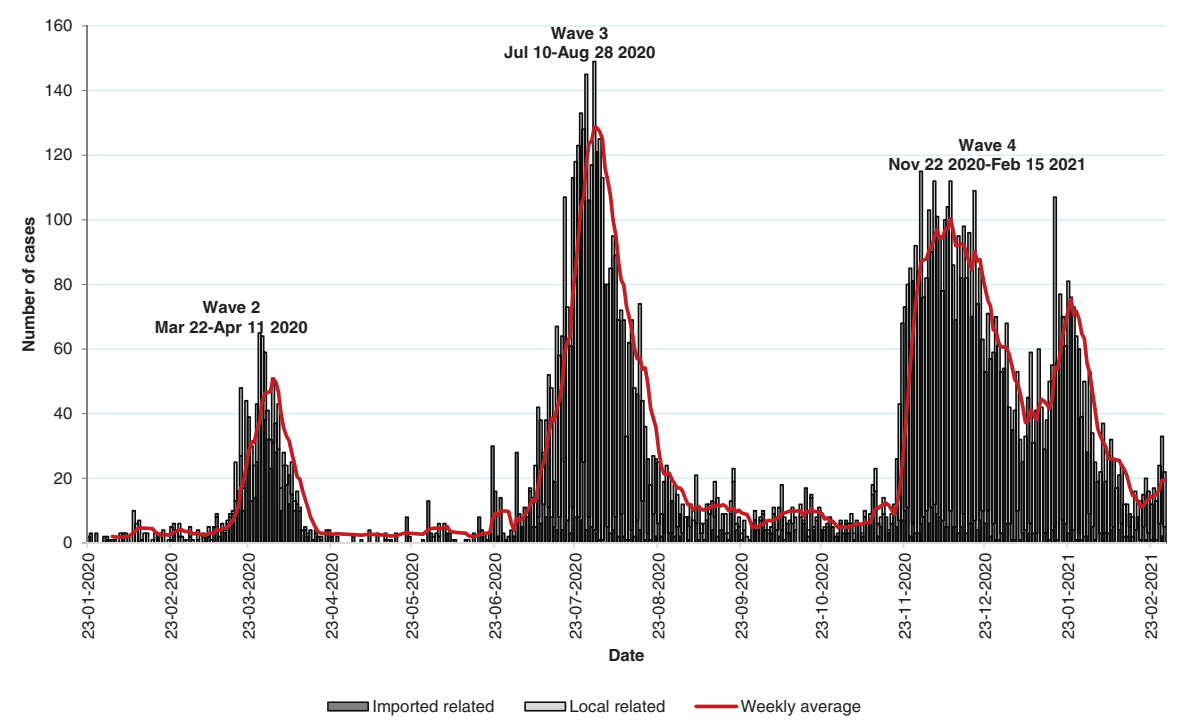

Data source: Hong Kong Center for Health Protection, Department of Health.

Note: The seven-day averages are the authors' own calculations.

migration to the spread of COVID-19, with large numbers of students and workingage citizens returning from emerging pandemic hotspot countries overseas. In this paper, we update those findings by compiling detailed case data in order to assess the shifts in demographic characteristics in the subsequent waves.

The paper is organised as follows. First, we explain the data and methods we used to conduct our analyses. Second, we present the characteristics of Hong Kong's COVID-19 outbreaks, and analyse the influence of socio-demographic factors on Hong Kong's vulnerability to the spread of the virus. We then examine and explain how local policy responses and social norms have shaped Hong Kong's unique experience of the pandemic. In particular, we discuss the contributions of border controls, quarantine requirements, social distancing measures, testing and tracing regimes, housing management, partial lockdowns, the efficient health care system, nursing home management and community actions.

\section{Data and methods}

Data on positive COVID-19 cases were drawn from the Centre for Health Protection (CHP) of the Hong Kong Department of Health. We reviewed the daily confirmed cases and the transmission types (local, local-related or imported-related), as well 
as the trend of the cumulative cases by age group from 23 January 2020 to 28 February 2021. Then, we calculated the seven-day averages of confirmed cases, which became our basis for defining the COVID-19 waves in Hong Kong. We defined these waves using a weekly average cut-off of 20 cases; i.e., a wave begins in the first week in which the average number of weekly cases is above 20, and ends in the week in which the average number of weekly cases falls below 20. Using this classification, we defined three waves of the pandemic, as shown in Figure 1. Wave 2 is from 22 March to 11 April $2020(n=683)$, Wave 3 is from 10 July to 28 August $2020(n=3,403)$ and Wave 4 is from 22 November 2020 to 15 February 2021 $(n=5,228)$. The officially defined "first wave" was excluded from our discussion because of the relatively small number of confirmed COVID-19 cases (fewer than 10 cases) that were reported during this period.

For each wave, we assessed the age and the sex distribution of the confirmed cases, and the mortality status of these cases. We calculated and analysed the overall case fatality rate (CFR) and broke it down by age and sex. The data on the geographical location of all known confirmed cases were drawn from the Centre for Health Protection Geodata dashboard. We also gathered data on the policy measures implemented in Hong Kong from government websites. For our comparative demographic analyses, we utilised the population estimate for the end of 2020 from the Hong Kong Census and Statistics Department.

\section{Characteristics of Hong Kong's COVID-19 outbreaks}

\subsection{The shifting age profile of COVID-19 cases}

Looking at Figure 2, we can see that there were major changes in the age structure of the cumulative confirmed cases in Hong Kong during our research period. Among the seven age groups, we observed the most drastic changes for the 15-24 and 65 and older age groups. Over time, the older population (aged 65+) replaced the younger population (aged 15-24) as the age group in Hong Kong with the highest proportion of total confirmed cases. By the end of the second wave (11 April 2020), the 15-24 age group accounted for $27.47 \%$ of the 1,001 cumulative confirmed cases; whereas the 65 and older age group accounted for just $7.69 \%$ of the total cases. However, by the end of the fourth wave (15 February 2021), the proportion of the 10,789 cumulative confirmed cases that were in the 15-24 age group had dropped to $10.35 \%$, while the proportion that were in the 65 and older age group had risen to $17.78 \%$.

We grouped the COVID-19 confirmed cases by waves, and in Figure 3 we present three comparable pyramids. Despite Hong Kong's rapidly ageing population, the confirmed COVID-19 cases in Wave 2 were initially concentrated among the younger age groups, with the largest incidence of cases reported in the 15-24 age group. Thus, we observed that during the first and second waves of COVID-19 in 
Figure 2:

Number of cumulative confirmed cases by age groups, Hong Kong ( $n=11,006$, 23 January 2020 to 28 February 2021)

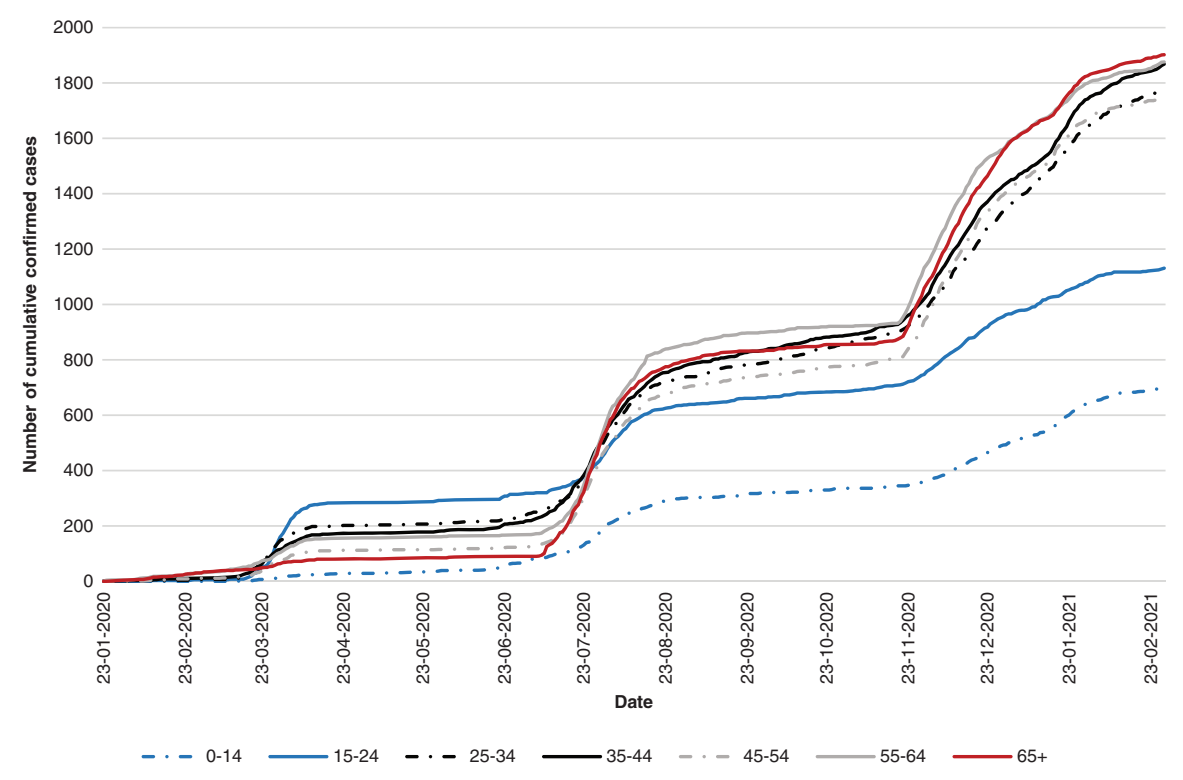

Data source: Hong Kong Center for Health Protection, Department of Health.

Hong Kong, the confirmed cases had a very different age distribution than that of the city's ageing population, with the highest number of cases occurring in the 1524 age group, and the majority (63.8\%) of positive cases occurring in the 15-44 age group (Cruz et al., 2020). By contrast, less than a tenth $(4.39 \%)$ of the cases occurred in the 65 and older age group. This age distribution of confirmed cases of COVID-19 was clearly very different from the general age profile of COVID19 cases in other countries during this period, where infections were concentrated among people in the older age groups (Dowd et al., 2020). However, in the third wave pyramid (Figure 3, Wave 3), the age profile of COVID-19 cases in Hong Kong had shifted dramatically. For example, the share of cases that occurred in the 15-24 age group decreased from $34 \%$ in Wave 2 to $9.3 \%$ in Wave 3, representing the largest drop in the percentage of confirmed cases among the age groups. Conversely, the share of cases that occurred in the 55-64 and 65+ age groups increased substantially, from $12.2 \%$ and $4.4 \%$, respectively, in Wave 2 to $19.5 \%$ for both groups in Wave 3 . In November 2020, the fourth and more protracted wave of the COVID-19 pandemic began in Hong Kong (Figure 3, Wave 4). In line with the pattern observed in the third wave, the cases in this wave were concentrated among the older age groups, with the highest shares of cases being reported among people in the 55-64 (17.0\%) and 
Figure 3:

Age and sex distribution of confirmed COVID-19 cases, Waves 2-4, Hong Kong
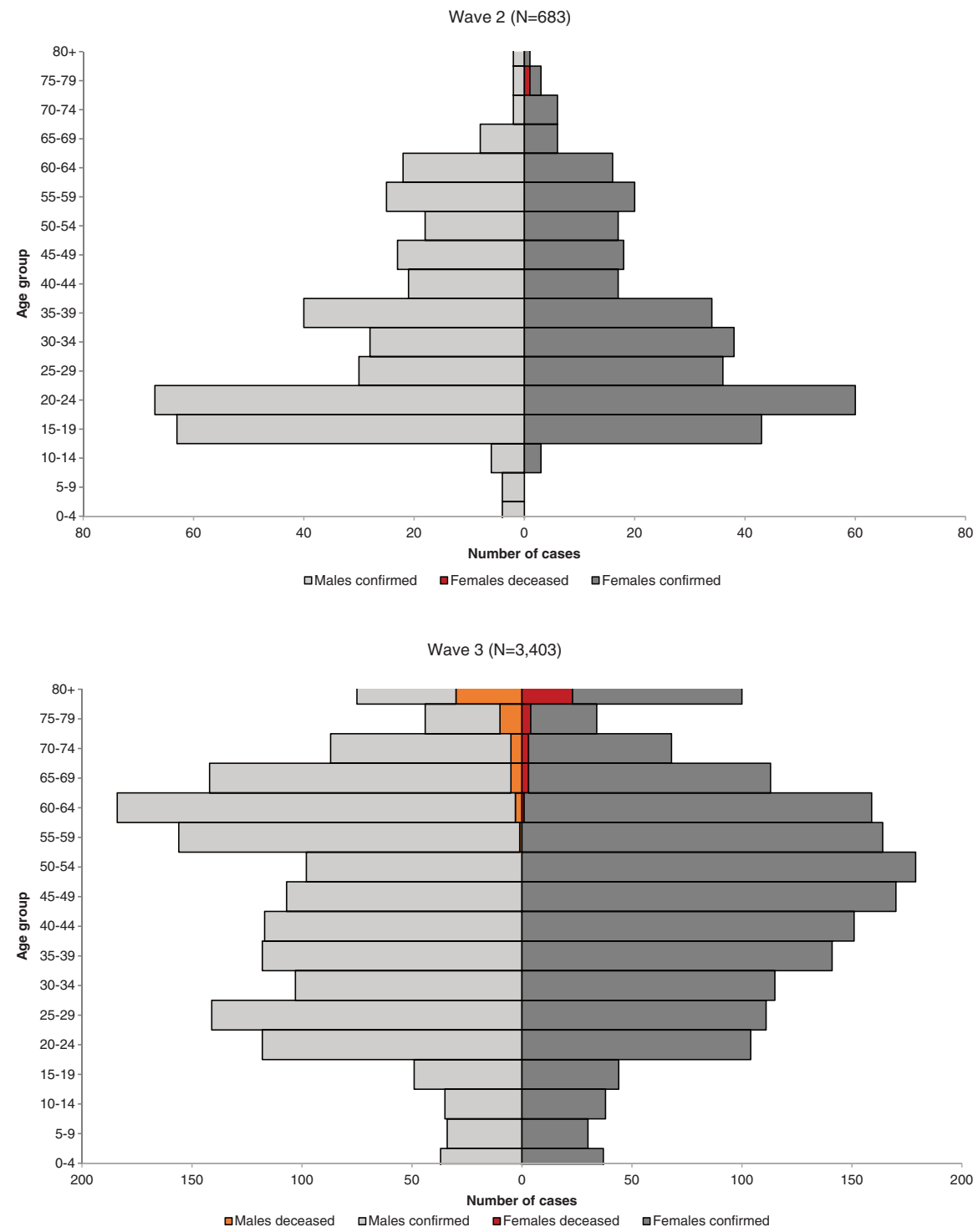

Continued 
Figure 3:

\section{Continued}

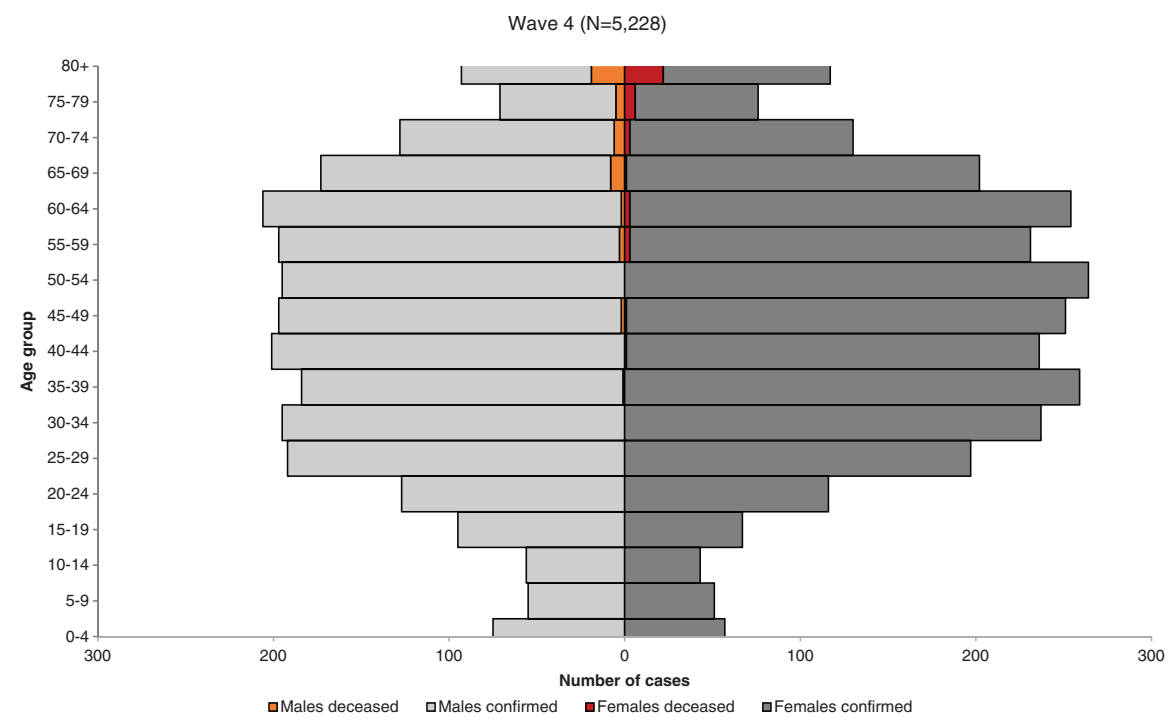

Data source: Hong Kong Center for Health Protection, Department of Health.

the $65+(18.9 \%)$ age groups. In stark contrast to the second wave, in the fourth wave the share of cases that occurred in the 15-24 age group was very low, at just $7.80 \%$.

\subsection{Low COVID-19 mortality and case fatality rates in Hong Kong}

Despite the shifting age profile of the confirmed cases, COVID-19 mortality in Hong Kong has remained low relative to the levels in other countries, at 2.7 deaths per 100,000 population. According to recent estimates, the three countries with the highest COVID-19 mortality rates are San Marino, Czechia and Belgium, with 237, 236 and 199 deaths per 100,000 population, respectively; while Cambodia has the lowest COVID-19 mortality rate, at 0.03 deaths per 100,000 (Johns Hopkins University and Medicine, 2021). Among the territories in East Asia, Hong Kong ranks third after Japan (seven deaths per 100,000 population) and South Korea (three deaths per 100,000 population). China, Mongolia and Taiwan Province of China (hereafter "Taiwan") have even lower COVID-19 crude mortality rates (below one death per 100,000 population) (Johns Hopkins University and Medicine, 2021).

In line with this trend of low but increasing mortality rates, the overall COVID-19 case fatality rate (CFR) in Hong Kong was $0.15 \%$ during the first two waves, and had increased to $2.6 \%$ in Wave 3. In the protracted Wave 4, the CFR was $1.6 \%$ as of 28 February 2021. Although comparisons of the CFR are challenging due to significant 
Table 1:

Case fatality rate $(\%)$ by gender and age groups, Hong Kong (23 January 2020 to 28 February 2021)

\begin{tabular}{lrrrrrrrr}
\hline & \multicolumn{2}{c}{ Males } & & \multicolumn{2}{c}{ Females } & & \multicolumn{2}{c}{ Both sexes } \\
\cline { 2 - 3 } Age group & \% & \multicolumn{1}{c}{$\boldsymbol{n}$} & & \% & $\boldsymbol{n}$ & & $\%$ & $\boldsymbol{n}$ \\
\hline $0-54$ & 1.0 & 3,446 & & 0.4 & 3,782 & & 0.7 & 7,228 \\
$55-59$ & 1.1 & 450 & & 0.6 & 469 & & 0.9 & 919 \\
$60-64$ & 1.1 & 470 & & 1.0 & 487 & & 1.0 & 957 \\
$65-69$ & 3.6 & 363 & & 1.1 & 359 & & 2.4 & 722 \\
$70-74$ & 6.0 & 252 & & 3.0 & 232 & & 4.5 & 484 \\
$75-79$ & 12.9 & 147 & & 12.0 & 125 & & 12.5 & 272 \\
$80+$ & 30.2 & 189 & & 20.9 & 235 & & 25 & 424 \\
ALL & 2.2 & 5,317 & & 1.5 & 5,689 & & 1.8 & 11,006 \\
\hline
\end{tabular}

Data source: Hong Kong Center for Health Protection, Department of Health.

Note: Calculations performed by authors.

differences between countries in the testing and reporting of confirmed COVID-19 cases and deaths, Hong Kong's total CFR from 23 January 2021 to 28 February 2021 has been estimated at $1.8 \%$ (Table 1), which is lower than the levels in many other global territories. The countries with the highest CFRs are Yemen (22\%), Mexico (9\%), Syria (7\%), Sudan (6\%) and Egypt (6\%); while Singapore has the lowest reported CFR, at less than $0.1 \%$ (Johns Hopkins University and Medicine, 2021). Hong Kong's overall COVID-19 CFR of $1.8 \%$ is comparable to the CFR estimates of its East Asian neighbours that also have ageing populations, like Japan (1.9\%), South Korea (1.7\%) and Taiwan (1.0\%) (Johns Hopkins University and Medicine, 2021).

\section{Factors shaping the Hong Kong COVID-19 experience}

\subsection{Socio-demographic risk factors and vulnerabilities}

Recent research has highlighted that certain socio-demographic conditions may facilitate the rapid spread of COVID-19 infections and deaths, such as a high proportion of older people in the population, high levels of institutional residence and intergenerational co-residence (extended family living together in a household), high population density, poor housing conditions and management, and a high number of foreign domestic workers.

Scholars have established a positive relationship between old-age population structures and COVID-19 mortality between territories; that is, the older the 
population, the higher the COVID-19 mortality rate (Farzanegan, 2020). Another study that examined 56 European areas highlighted the relationship between ageing and COVID-19 mortality, reporting a positive relationship between the median age and the case fatality rate (i.e., the case fatality rates increase as the median age increases) (Wang et al., 2020). As we noted above, during the first two waves of the COVID-19 pandemic in Hong Kong, only around 10\% of the 683 confirmed cases occurred in the 60+ age group, and there was only one death during this period. Hong Kong's very low mortality rate in the first and second waves is largely attributable to the infection being concentrated in the younger population (Cruz et al., 2020). However, during Waves 3 and 4, infection rates among older age groups increased, accounting for about $30 \%$ of the total number of confirmed cases. The number of deaths also increased, with nearly all deaths occurring in the older age groups. The shift in Hong Kong in the age profile of COVID-19 infections and deaths away from the younger population and towards the older population follows the observed global pattern, which highlights the vulnerability of older people to the virus. In addition, research has shown that within territories, the general pattern of COVID-19 death rates is that they increase with age, and that men have a higher risk than women of dying from COVID-19 (Chamie, 2021; Hoffmann and Wolf, 2021; Undurraga et al., 2021). This pattern was also evident during Waves 3 and 4 of the Hong Kong pandemic, as the CFR increased with age, and there were more COVID-19-related deaths among older men than older women (see Table 1).

In addition to the share of older people in the population, a second factor that may have increased Hong Kong's level of vulnerability to COVID-19 mortality is the prevalence of older people living in residential care facilities. As an ageing society in which about $18 \%$ of the population are over the age of 65 (Wong and Yeung, 2019), care homes have increasingly become a residential option for older people in Hong Kong. According to the statistics released by Hong Kong's Elderly Commission in 2009, around 7\% of older people aged 65 and older were living in residential facilities, compared to $2-3 \%$ in other Asian regions and $3-4 \%$ in some western societies (e.g., Canada and the US) (Elderly Commission of Hong Kong, 2009). By 2016, the proportion of older people in Hong Kong who were living in residential facilities had risen to $8.5 \%$ (Research Office of the Hong Kong Legislative Council Secretariat, 2017). Researchers have established the extreme vulnerability of nursing homes and other residential facilities around the world to the spread of COVID-19 and to high mortality from the virus. For example, it has been shown that a substantial proportion of COVID-19 deaths in the US have been among care home residents (Wagner, 2020).

Moreover, it has been observed that "intergenerational interactions, co-residence, and commuting may have accelerated the outbreak in Italy through social networks that increased the proximity of elderly to initial cases" (Dowd et al., 2020, 1). This also describes a potential COVID-19 transmission chain in Hong Kong, as coresidence is common in the city $(\mathrm{Ko}, 2012)$, with around half of older people living with their adult children (Tong et al., 2019). This prevalence of co-residence is much higher than it is in North America and Europe, where, apart from an exceptionally 
high prevalence of $61 \%$ in Albania, the proportion of older people who live with their family ranges from 6\% in the Netherlands to $36 \%$ in Romania (United Nations, Department of Economic and Social Affairs, Population Division, 2017). Hong Kong's extremely high population density and efficient transport systems also make it easy for older adults and their adult children or grandchildren to remain in regular contact. In addition, during all waves of the pandemic, there have been no legal restrictions on gatherings in private residences. An analysis of confirmed cases in Hong Kong that were transmitted through local infections during the first and second waves showed that $54.4 \%$ of cases were transmitted through households, $33.1 \%$ of cases were transmitted through social settings outside the home and $11.9 \%$ of cases were transmitted through work settings (Adam et al., 2020). However, these results may be biased somewhat by the fact that the tracing of case contacts is significantly easier among families than it is among strangers in social settings.

Another socio-demographic factor that is critical to Hong Kong's vulnerability to the spread of COVID-19 is the very high level of population density. Multiple studies have found connections between population density and the spread of COVID-19 in Iran (Ahmadi et al., 2020), Turkey (Coşkun et al., 2021) and Japan (Kodera et al., 2020). Hong Kong certainly faces a high risk of COVID-19 transmission because of its extremely high population density and poor housing conditions in certain districts. Due to the limited availability of residential land in the territory, many residents live in extremely small and cramped apartments, and the conditions are especially concerning for low-income residents. In 2016, an estimated 209,700 people in Hong Kong were living in subdivided flats (Census and Statistics Department, 2016), which are sometimes referred to as "coffin houses" because of their tiny size and very cramped conditions (Wong, 2018). In 2016, there were 27,100 such apartments divided into an average of 3.4 subdivided units, with each subdivided unit housing an average of 2.3 persons (Census and Statistics Department, 2016). The median floor space per resident was just 5.3 square metres. These flats are characterised by poor hygiene and sanitation, environmental concerns (Lai et al., 2017) and safety problems (Leung and Cheuk, 2016). The districts with the highest numbers of subdivided flats are Yau Tsim Mong, Sham Shui Po and Kowloon City, all of which are located in the Kowloon region. Hong Kong also has a number of so-called "three-nil buildings", which have no apparent owner, and are not overseen by a property management corporation or a resident organization. Because they lack effective management, these buildings tend to be poorly maintained and dilapidated, particularly since many of them are old buildings (Hong Kong Government, 2019). In 2019, there were 5,300 of these buildings, primarily located in districts of the Kowloon region (Hong Kong Government, 2019). In areas with this extreme building density - which is generally associated with lower wind and air ventilation - and high building heights, a higher incidence of COVID-19 cases has been observed (Kwok et al., 2021). Thus, poor housing conditions and inadequate building management exacerbate the impact of high population density in Hong Kong, which, in turn, means that more people in the city are vulnerable to COVID-19 infections. 
Another demographic vulnerability in Hong Kong is the proportion of low-wage migrant workers in the population, as the experiences of other territories indicate that people in this demographic group are at significantly higher risk of catching COVID-19 due to their often cramped housing conditions. Moreover, migrant workers tend to be employed in occupations that require physical labour, and that do not provide opportunities for "teleworking", or working from home. During the second wave of the pandemic in Singapore, for example, more than half of the purpose-built and factory-converted dormitories for guest workers were affected by COVID-19 outbreaks (Humanitarian Organisation for Migration Economics, 2020). It has been estimated that around $80 \%$ of all cases during the second wave in Singapore were linked to these dormitories (Humanitarian Organisation for Migration Economics, 2020). Hong Kong is also home to a large population of migrant "guest workers" who may be vulnerable to spread of the virus. Most of these workers are classified as "Foreign Domestic Workers" (FDWs), and are required to live in their employer's home. In 2019, there were almost 400,000 migrant domestic workers in Hong Kong, making up more than $10 \%$ of the city's labour force (Labour and Welfare Bureau, 2019). The overwhelming majority of these migrant workers are women from Southeast Asia. These workers run a particularly high risk of catching COVID-19 because their jobs entail intra-household and, often, inter-household relations.

\subsection{Protective factors: Policy responses and community actions}

Two notable shifts occurred in the profile of confirmed COVID-19 cases in Hong Kong from wave to wave: i.e., a shift in the age profile of cases from younger to older ages, and a shift from imported to local transmission. In our previous analysis, we attributed a large proportion of the positive cases to members of the student-age and working-age populations returning to Hong Kong from COVID-19 hotspots in the initial stages of the pandemic. We showed that most of the confirmed cases in the first and second waves were imported, and we highlighted the important role of members of the Hong Kong diaspora, and particularly of the large overseas student population, who had returned to Hong Kong from COVID-19 hotspot areas overseas (Cruz et al., 2020). An analysis of detailed travel history data tracked by the CHP revealed that of the COVID-19 cases involving an individual with an overseas travel history, nearly half (47.4\%) were imported from the United Kingdom (UK), 9.1\% were imported from the United States (US), and 3.9\% each were imported from Qatar, Canada and Switzerland (Cruz et al., 2020). In addition, our research found that a very high proportion of the confirmed cases in the 15-24 age group (90\%) and the 25-34 age group (43\%) could be classified as "imported-related" (i.e., cases that were imported from overseas or could be directly linked to an imported case). However, throughout the third and fourth waves, strict border controls designed to prevent or greatly discourage overseas travel vastly reduced travel in and out 
of Hong Kong. In line with these reductions in travel, a minority of cases in the third and fourth waves were imported. Thus, during these waves, the pandemic was driven by the local spread of COVID-19. The results of our analysis indicate that a significantly lower proportion of cases in the third and fourth waves were imported, with such cases accounting for $35.8 \%$ of the total confirmed cases during the third wave, and just $7.6 \%$ of the total confirmed cases during the fourth wave (see Figure 1).

It is, however, of critical importance that government-mandated border controls changed over time and helped to mitigate the increase in imported and related cases in Hong Kong. From 25 March 2020 onwards, all non-residents were barred from entering the territory except for nationals of Macau Special Administrative Region of the People's Republic of China (hereafter "Macau"), Taiwan or Mainland China. By the end of March 2020, new 14-day home quarantine requirements were put in place for all people arriving in the city, regardless of whether they were residents. As a result of these requirements, passenger traffic decreased sharply. The longer-term effect of these policies was to dampen inbound travel for the rest of 2020, which undoubtedly contributed to the significantly lower proportion of imported cases in later waves. According to the data we retrieved from the Hong Kong Immigration Department, the number of people arriving in the city remained at around 25,000 per day before dropping significantly at the end of March 2020 to below 2,000. Government-mandated border controls as well as aggressive test-and-trace and quarantine regulations contributed to the decline in COVID-19 cases during the month of April 2020 (Cowling et al., 2020). During the third wave, strict border controls remained in place, and travel quarantine requirements became even more stringent. For example, although residents were initially permitted to quarantine at home, they were issued a tracking bracelet connected to the Global Positioning System (GPS), and were tested for COVID-19 before and during the quarantine period.

In addition, on 25 July 2020, the government introduced a list of "high-risk" territories. Travellers from these locations were subject to stricter quarantine requirements, including rules mandating that they have a negative test before travelling and spend the quarantine period in a government-designated hotel (Hong Kong Government, 2020b). These restrictions contributed to the significantly lower numbers of imported confirmed cases in the third wave than in the second wave, during which the cases were concentrated among younger age groups.

As the fourth wave of COVID-19 in Hong Kong - which was linked to transport staff - started prior to the holiday season in December 2020, the border control and quarantine regulations were further tightened to protect Hong Kong from international transmission. In November 2020, the government introduced new travel restrictions and expanded the 14-day hotel quarantine requirement to cover travellers who entered Hong Kong from any destination except Taiwan, Macau and Mainland China. The UK, the US, France and Germany were added to the list of high-risk countries, which already included many countries in Asia, such as Indonesia, the Philippines, India, Nepal and Pakistan. Under these newly imposed 
restrictions, travellers also had to secure a negative COVID-19 test 72 hours before arriving in Hong Kong. On 25 December 2020, the length of the mandatory hotel quarantine was extended to 21 days for travellers arriving from all regions except Taiwan, Macau and Mainland China. At that time, this was the longest travel quarantine period in the world. In addition, all travel was banned from the UK and South Africa, including for Hong Kong residents. According to the travel data retrieved from the Hong Kong Immigration Department, the numbers of inbound and outbound travellers remained very low from December 2020 to February 2021, and thus over the Christmas and Lunar New Year holidays, which are usually the busiest travel period for Hong Kong. During this period, the daily average number of arrivals was lower than 2,000, and the daily average number of departures was around 2,500. Hong Kong has a large overseas population of secondary school- and university-age students, especially in the UK and the US, and a large share of Hong Kong residents are also nationals of the UK, the US and Canada. These populations are believed to have triggered the second wave outbreak in Hong Kong (Cruz et al., 2020). In addition, Hong Kong is home to large populations of nationals from the Philippines, Indonesia, India, Nepal and Pakistan (Cruz et al., 2020). Given that all of these countries imposed even stricter travel regulations from November 2020 onwards, it is likely that these restrictions strongly discouraged travel, leading to significantly lower numbers of imported cases in the fourth wave than in the two earlier waves.

In addition to border control measures designed to limit the number of imported cases, another set of critical policy tools used by the Hong Kong government were social distancing measures aimed at mitigating local transmission. These social distancing regulations were generally implemented when needed, and were adapted to the local pandemic conditions. These measures included reductions in the opening hours of restaurants; restrictions on the sizes of public gatherings; and closures of schools, universities, entertainment venues, recreational facilities, outdoor spaces and certain types of businesses, such as gyms, bars, nightclubs, beauty salons, massage parlours, sports and exercise facilities, beaches and playgrounds. Although these measures clearly had deleterious effects on local businesses, social activities and social interactions, the evidence suggests that from a public health perspective, they were effective in containing the spread of COVID-19. For example, research indicates that during the second wave of the pandemic in Hong Kong, a combination of adherence to social distancing and mask-wearing regulations, remote working and school closures led to a reduction in seasonal influenza incidence of around $44.0 \%$ (Cowling et al., 2020).

A third set of key government policies designed to reduce local transmission chains were testing and tracing measures. Under these rules, anyone who had come into contact with a confirmed case was pre-emptively placed in a government isolation centre for 14 days and tested regularly. It has been shown that these very thorough contact tracing processes and strict quarantine requirements were highly effective in interrupting chains of transmission during the first and second waves 
(Adam et al., 2020), and may have played a role in mitigating the local spread of the virus.

Although the city's high population density and poor housing conditions in many communities posed risks for Hong Kong during the pandemic, the government attempted to compensate for these disadvantages by deploying various policy measures, most notably measures related to housing and building management, as well as community-level lockdowns. The Housing Authority (HA) implemented a number of public health measures after the start of the pandemic, such as the intensification of daily cleaning and disinfection in public areas, including of escalators, elevators, passages and drainage facilities. Whenever a COVID-19 case was confirmed by the Department of Health, the HA arranged for the thorough cleaning and disinfection of the affected buildings, and conducted comprehensive inspections of any units that shared sewerage and pipes with the unit in which the confirmed case was detected. The authority also distributed and collected voluntary testing bottles from residents, and collected environmental samples from affected public facilities (Hong Kong Housing Authority, 2020). During the fourth wave, the government imposed numerous partial lockdowns - i.e., compulsory testing orders of certain residential blocks. These lockdowns were, for example, implemented in response to concerns about a number of community clusters that emerged in several districts in Kowloon (Jordan, Yau Ma Tei, and Sham Shui Po) with population densities of more than 48,930 persons per square kilometre. The first of these partial lockdowns centred on several housing blocks in Jordan, a district in which high proportions of the residents have lower socio-economic status and are members of ethnic minority groups. On 23 January 2021, more than 3,000 government staff including 1,600 so-called "disciplinary workers" - locked down an area of around 70 buildings in Jordan, Kowloon, and conducted more than 7,000 COVID-19 tests (Hong Kong Government, 2021a). Numerous other community-level lockdowns have since been implemented in residential blocks spread around the city that were suspected of having clusters of COVID-19 cases. Given that these small COVID-19 outbreaks across various parts of the city were indeed brought under control, it is clear that these policy actions helped to stem the spread of the virus in the most cramped housing blocks.

The relatively low mortality and case fatality rates due to COVID-19 in Hong Kong are remarkable given the territory's large older population and the high proportion of its residents living in residential care homes, as studies have shown that there is a strong relationship between having an older population age structure and high COVID-19 mortality (Hoffmann and Wolf, 2020, 2021). As the results of our previous analysis suggested, one key, yet often overlooked factor in these relatively low mortality rates is the distribution of confirmed cases during the first few months of the COVID-19 pandemic, which were concentrated among the younger age groups in Hong Kong (Cruz et al., 2020) However, by the third and fourth waves of the pandemic in Hong Kong, the CFR in the city was clearly exhibiting the expected pattern: i.e., it was increasing with age, and was especially high among older men. Nonetheless, the CFR in Hong Kong remained lower 
than the rates in most other territories. A second important set of factors in the relatively low mortality and case fatality rates in Hong Kong are, most likely, the city's effective health care system and its coordinated management of residential facilities from the start of the pandemic. Based on the lessons the city learned during the 2003 outbreak of severe acute respiratory syndrome (SARS), the Hong Kong Department of Health directed all residential care homes at the start of the COVID-19 pandemic to assign a staff member to manage infection control and implement preventive measures. These staff members were expected to implement measures such as the limitation/suspension of family visits, the restriction of the movement of residents outside the facility, social distancing, and the wearing of face masks (Chow, 2021; Woo, 2020). Meanwhile, the Hong Kong government also issued guidelines to support residential care homes in preventing infection (Centre for Health Protection, 2020), and offered other forms of support, including the provision of personal protective equipment (PPE) and infection protection services (Hong Kong Government, 2020c), as well as the transition to online care support for individuals who would ordinarily visit day care centres (Xinghui et al., 2020). Research has shown that the implementation of stringent COVID-19 guidelines and prevention measures has been highly effective in preventing the spread of infection (McMichael et al., 2020). Thus, it is likely that the strict preventive measures implemented in Hong Kong care homes from the beginning of the pandemic may have created fewer opportunities for sustained local spread within the older population. In addition, some studies have linked the low mortality and case fatality rates in Hong Kong to the city's strong overall health care system and testing and quarantine regimes (Farzanegan, 2020; Lui et al., 2020). Farzanegan found that the risk of death from COVID-19 has been lower in ageing societies with at least 3.5 hospital beds per 1,000 population (Farzanegan, 2020). Our results appear to support this finding, as based on our estimates of the numbers of beds in public and private hospitals as of May 2019 (Hong Kong Department of Health, 2019) and of the population as of the end of December 2020 (Census and Statistics Department, 2021), the current hospital bed capacity in Hong Kong is approximately 4.5 hospital beds per 1,000 population.

Moreover, even though migrant workers have been identified in other regions as a high-risk population during the coronavirus pandemic, the spread of COVID19 among migrant workers in Hong Kong has been extremely low. It is likely that government policies in conjunction with community actions among groups of migrant workers have greatly reduced the transmission of COVID-19 in Hong Kong. In terms of government policies since the second wave of the pandemic, the government has advised local employers of FDWs to discourage employees from socialising in public places during periods of social distancing, and has mandated that such gatherings can be broken up by the police, and that the participants can be fined. It is also likely that travel policies and flexible contract and immigration arrangements for FDWs played a very important role in reducing the spread of the virus among this population. To discourage migrant workers from travelling between Hong Kong and their home countries, the government offered to extend the visas of those individuals 
whose visas were about to expire. In August 2020, the Philippines and Indonesia, the biggest migrant sending countries, were added to the list of high-risk countries, and a two-week hotel quarantine for travellers from these countries was put in place. Employers of FDWs travelling from these countries were required to sign an agreement to pay for a hotel stay and testing for each employee (Hong Kong Government, 2021b). In line with the general tightening of travel restrictions, from December 2020 onwards, FDWs travelling to work in Hong Kong were required to stay in a government-designated hotel for 21 days. In addition to these efforts by the government, community actions among groups of migrant workers may have also contributed the low rates of infection among this group. These actions included mask-wearing, social distancing and taking advantage of the free COVID-19 testing that was made available to FDWs (Hong Kong Government, 2020a).

As well as the policies implemented by the government, community actions appeared to be remarkably successful in preventing the rapid spread of COVID19, particularly in the initial stages of the pandemic. Citizens of Hong Kong were on high alert as early as in January 2020, when the Chinese government officially reported a cluster of cases of pneumonia in Wuhan, Hubei Province. For example, the general public overwhelmingly started wearing masks at the beginning of the local COVID-19 pandemic (Cheng et al., 2020), despite a lack of government advice to do so. Mask-wearing was already a common practice in Hong Kong, as it had been used to control the community transmission of SARS in 2003, and then the pandemic influenza A-H1N1 in 2009. It is also believed that these experiences contributed substantially to the community's high levels of compliance with many other non-pharmaceutical measures, including social distancing, border controls and quarantine requirements (Cheng et al., 2020). For example, evidence from three cross-sectional, representative telephone surveys during the first and second waves indicates that the vast majority of the population engaged in the rapid uptake of behaviours aimed at preventing the spread of COVID-19. By mid-February, around 20 days after the first case was announced, $97.5 \%$ of residents reported using face masks, 92.5\% reported washing their hands more often, $90.2 \%$ said they were avoiding going to crowded places and $89.3 \%$ reported that they had disinfected their home in response to the pandemic (Cowling et al., 2020). Although the proportion of people who said they were avoiding public places had dropped slightly by midMarch, rates of face mask-wearing and hand-washing remained extremely high (Cowling et al., 2020).

\section{Conclusion}

Research has suggested that places that have an ageing population structure, high population density and cramped living conditions, and a high proportion of migrants in the population are at high risk of experiencing the rapid spread of COVID-19 and high mortality rates from the virus (Goldstein and Lee, 2020; Humanitarian Organisation for Migration Economics, 2020). However, despite fitting all these 
criteria, the COVID-19 infection rates in Hong Kong have been much lower than those in many global territories, and the mortality rates in the city have been correspondingly low. The collective efforts by the government, the private sector and the public through targeted policies and community actions may have helped Hong Kong overcome its aforementioned significant socio-demographic vulnerabilities to COVID-19. Our analysis has highlighted the importance of travel histories and border restrictions in explaining the shift in the age structure of cases across waves. Border closures, travel bans and quarantine requirements significantly deterred inbound and outbound travel, resulting in lower numbers of imported cases in later waves, which had previously been clustered in the younger age groups. We highlighted the effectiveness of social distancing, testing and tracing, housing management and partial lockdowns in mitigating the local transmission of the COVID-19 virus. In seeking to explain the low COVID-19 mortality rates in Hong Kong despite the city's ageing population, we noted the role of the age profile of cases, but also emphasised the importance of the city's efficient health care system and nursing home management. The combination of all of these efforts proved effective in slowing down or even stopping the spread of infections in Hong Kong.

Furthermore, public health experts see hope in the rollout of safe COVID-19 vaccines around the world (Kasai, 2021). In Hong Kong, the vaccination rollout started at the end of February 2021, and as of 10 August 2021, 51.9\% and 40.0\% of the total population had been vaccinated with the first and the second dose, respectively (Hong Kong Government, 2021c). However, relative to many other countries, "vaccine hesitancy" is high and the general acceptance of vaccines is low in Hong Kong (Yu et al., 2021). To address this slow uptake, medical experts have recommended that all relevant actors help through "intensive education, provision of more evidence-based information, and public health interventions" (Chan et al., 2021).

\section{ORCID}

Zilin $\mathrm{Li}{ }^{\circledR}$ https://orcid.org/0000-0002-5041-0871

Stuart A. Gietel-Basten ${ }^{(0)}$ https://orcid.org/0000-0002-5818-8283

Rachel Ganly (D) https://orcid.org/0000-0002-0352-8412

Christian Joy Pattawi Cruz ${ }^{(1)}$ https://orcid.org/0000-0001-6328-2656

\section{References}

Adam, D. C., Peng Wu, Jessica Y. Wong, Eric H. Y. Lau, Tim K. Tsang, Simon Cauchemez, Gabriel M. Leung, and Benjamin J. Cowling. (2020). Clustering and superspreading potential of SARS-CoV-2 infections in Hong Kong. Nature Medicine, 26(11), 1714-19. https://doi.org/10.1038/s41591-020-1092-0 
Ahmadi, M., Sharifi, A., Dorosti, S., Jafarzadeh Ghoushchi, S., and Ghanbari, N. (2020). Investigation of effective climatology parameters on COVID-19 outbreak in Iran. The Science of the Total Environment, 729, Article 138705. https://doi.org/10.1016/j.scitotenv. 2020.138705

Census and Statistics Department. (2016). Thematic report: Persons living in subdivided units. Census and Statistics Department.

Census and Statistics Department. (2021). Population. Census and Statistics Department The Government of the Hong Kong Special Administrative Region. https://www.censtatd. gov.hk/hkstat/sub/so20.jsp

Chamie, J. (2021). COVID-19 pandemic: Demographic highlights. IUSSP's Online News Magazine. 22 March 2021. https://www.niussp.org/article/covid-19-pandemicdemographic-highlights/

Chan, P. K. S., Martin, C., Wong, S., and Wong, E. L. Y. (2021). Vaccine hesitancy and COVID-19 vaccination in Hong Kong. Hong Kong Medical Journal = Xianggang Yi Xue Za Zhi/Hong Kong Academy of Medicine, 27(2), 90-91. https://doi.org/10.12809/ hkmj219639

Cheng, V. C.-C., Wong, S.-C., Chuang, V. W.-M., Yung-Chun So, S., Hon-Kwan Chen, J., Sridhar, S., Kai-Wang To, K., et al. (2020). The role of community-wide wearing of face mask for control of coronavirus disease 2019 (COVID-19) epidemic due to SARS-CoV-2. The Journal of Infection, 81(1), 107-14. https://doi.org/10.1016\%2Fj.jinf.2020.04.024

Chow, L. (2021). Care homes and COVID-19 in Hong Kong: How the lessons from SARS were used to good effect. Age and Ageing, 50(1), 21-24. https://doi.org/10.1093/ageing/ afaa234

Centre for Health Protection. (2020). Guidelines for residential care homes for the elderly or persons with disabilities for the prevention of coronavirus disease (COVID-19) (Interim). Center for Health Protection. https://www.chp.gov.hk/files/pdf/advice_to_rche_rchd_on_ prevention_of_nid_eng.pdf

Coşkun, H., Yıldırım, N., and Gündüz, S. (2021). The spread of COVID-19 virus through population density and wind in turkey cities. The Science of the Total Environment, 751, Article 141663. https://doi.org/10.1016/j.scitotenv.2020.141663

Cowling, B. J., Ali, S. T., Ng, T. W. Y., Tsang, T. K., Li, J. C. M., Fong, M. W., Liao, Q., Kwan, M. Y. W., Lee, S. L., Chiu, S. S., Wu, J. T., Wu, P., and Leung, G. M. (2020). Impact assessment of non-pharmaceutical interventions against coronavirus disease 2019 and influenza in Hong Kong: An observational study. Lancet Public Health, 5, e279-e288. https://doi.org/10.1016/S2468-2667(20)30090-6

Cox, W. (2021). Demographia International Housing Affordability. Urban Reform Institute.

Cruz, C., Pattawi, J., Ganly, R., Li, Z., and Gietel-Basten, S. (2020). Exploring the young demographic profile of COVID-19 cases in Hong Kong: Evidence from migration and travel history data. PLoS One, 15(6), Article e0235306. https://doi.org/10.1371/journal. pone.0235306

Dowd, J. B., Andriano, L., Brazel, D. M., Rotondi, V., Block, P., Ding, X., Liu, Y., and Mills, M. C. (2020). Demographic science aids in understanding the spread and fatality rates of COVID-19. Proceedings of the National Academy of Sciences of the United States of America. https://doi.org/10.1073/pnas.2004911117 
Elderly Commission of Hong Kong. (2009). Study on residential care services for the elderly. https://www.elderlycommission.gov.hk/en/download/library/Residential\% 20Care\%20Services\%20-\%20Final\%20Report(eng).pdf

Farzanegan, M. R. (2020). Ageing society and SARS-CoV-2 mortality: Does the healthcare absorptive capacity matter? Journal of Risk and Financial Management, 13(11), Article 277. https://doi.org/10.3390/jrfm13110277

Goldstein, J. R., and Lee, R. D. (2020). Demographic perspectives on the mortality of COVID19 and other epidemics. Proceedings of the National Academy of Sciences of the United States of America, 117(36), 22035-22041. https://doi.org/10.1073/pnas.2006392117

Hoffmann, C., and Wolf, E. (2020). The low case fatality rate of COVID-19 in Hong Kong could be deceptive. Clinical Infectious Diseases: An Official Publication of the Infectious Diseases Society of America, 73(7), e1781-e1782. https://doi.org/10.1093/cid/ciaa1676

Hoffmann, C., and Wolf, E. (2021). Older age groups and country-specific case fatality rates of COVID-19 in Europe, USA and Canada. Infection, 49(1), 111-16. https://doi.org/10. 1007/s15010-020-01538-w

Hong Kong Department of Health. (2019). Health facts of Hong Kong: 2019 edition. Health Facts of Hong Kong. https://www.dh.gov.hk/english/statistics/statistics_hs/files/Health_ Statistics_pamphlet_E.pdf

Hong Kong Government. (2019). Providing support for owners of three-nil buildings. LCQ12. Hong Kong Government. https://www.info.gov.hk/gia/general/202001/ 15/P2020011400595.htm

Hong Kong Government. (2020a). Helpers' Virus Testing to Continue. 24 December 2020. https://www.news.gov.hk/eng/2020/12/20201224/20201224_130956_610.html

Hong Kong Government. (2020b). Measures for Travellers Gazetted. 18 July 2020. https://www.news.gov.hk/eng/2020/07/20200718/20200718_133240_725.html? type $=$ category $\&$ name $=$ covid $19 \& \mathrm{tl}=\mathrm{t}$

Hong Kong Government. (2020c). Virus Prevention for Care Homes. 22 March 2020. https: //www.news.gov.hk/eng/2020/03/20200321/20200321_195715_498.html

Hong Kong Government. (2021a). Restrictions in Jordan Lifted. 25 January 2021. https: //www.news.gov.hk/eng/2021/01/20210125/20210125_111513_562.html

Hong Kong Government. (2021b). New Foreign Helper Visa Rules Set. 21 July 2021. https: //www.news.gov.hk/eng/2020/07/20200721/20200721_194754_493.html

Hong Kong Government. (2021c). Hong Kong Vaccination Dashboard. Retrieved 10 August 2021, from https://www.covidvaccine.gov.hk/en/

Hong Kong Housing Authority. (2020). Housing Authority's Response to 'The Housing Authority's Anti-Epidemic Arrangements for Public Housing Under the Fourth Wave of Epidemic. December 2020. https://www.districtcouncils.gov.hk/ssp/doc/2020_2023/sc/ committee_meetings_doc/HAC/17832/HAC_6th_151_tc.pdf

Humanitarian Organisation for Migration Economics. (2020). COVID-19 Impact Report 2020. https://static1.squarespace.com/static/5a12725612abd96b9c737354/t/ 6058491850fef20618c9c202/1616398685334/HOME+Covid+Report+FINAL.pdf

Johns Hopkins University and Medicine. (2021). Mortality Analyses. Johns Hopkins University and Medicine Coronavirus Resource Center. Retrieved 24 March 2021, from https://coronavirus.jhu.edu/data/mortality 
Kasai, T. (2021). COVID-19 Vaccines Offer Hope, Other Prevention Measures Must Continue. WHO. https://www.who.int/westernpacific/news-room/commentaries/detail-hq/covid-19vaccines-offer-hope-but-other-prevention-measures-must-continue

Kodera, S., Rashed, E. A., and Hirata, A. (2020). Correlation between COVID-19 morbidity and mortality rates in Japan and local population density, temperature, and absolute humidity. International Journal of Environmental Research and Public Health, 17(15). https://doi.org/10.3390/ijerph17155477

Ko, L. S. F. (2012). Solidarity, ambivalence and multigenerational co-residence in Hong Kong. In S. Arber and V. Timonen (Eds.), Contemporary grandparenting: Changing family relationships in global contexts (pp. 91-112). University Press Scholarship Online. https://doi.org/10.1332/policypress/9781847429681.003.0005

Kwok, Coco Yin Tung, Man Sing Wong, Ka Long Chan, Mei-Po Kwan, Janet Elizabeth Nichol, Chun Ho Liu, Janet Yuen Ha Wong, et al. (2021). Spatial analysis of the impact of urban geometry and socio-demographic characteristics on COVID-19, a study in Hong Kong. The Science of the Total Environment, 764, Articl1e 44455. https://doi.org/10.1016/ j.scitotenv.2020.144455

Labour and Welfare Bureau. (2019). Legislative Council Panel on Manpower Foreign Domestic Helpers' Access to Healthcare Services. LC Paper No. CB(2)1186/18-19(03).

Lai, Ka Man, Ka Man Lee, and William Yu. (2017). Air and hygiene quality in crowded housing environments - a case study of subdivided units in Hong Kong. Indoor and Built Environment, 26(1), 32-43. https://doi.org/10.1177\%2F1420326X15600042

Leung, K. K., and Cheuk Lun Chow. (2016). A brief discussion on fire safety issues of subdivided housing units in Hong Kong. Proceedings of the 3rd Residential Building Design and Construction Conference, State College, PA, USA, 2-3 March 2016.

Lui, G. C.-Y., Yip, T. C.-F., Wong, V. W.-S., Chow, V. C.-Y., Ho, T. H.-Y., Li, T. C.-M., Tse, Y.-K., Chan, H. L.-Y., Hui, D. S.-C., and Wong, G. L.-H. (2020). Significantly lower case-fatality ratio of coronavirus disease 2019 (COVID-19) than severe acute respiratory syndrome (SARS) in Hong Kong-A territory-wide cohort study. Clinical Infectious Diseases, 72(10), e466-e475. https://doi.org/10.1093/cid/ciaa1187

McMichael, T. M., Clark, S., Pogosjans, S., Kay, M., Lewis, J., Baer, A., Kawakami, V., Lukoff, M. D., Ferro, J., Brostrom-Smith, C., Riedo, F. X., Russell, D., Hiatt, B., Montgomery, P., Rao, A. K., Currie, D. W., Chow, E. J., Tobolowsky, F., Bardossy, A. C., ..., Duchin, J. S., Public Health - Seattle \& King County, EvergreenHealth, and CDC COVID-19 Investigation Team. (2020). COVID-19 in a long-term care facilityKing County, Washington, February 27-March 9, 2020. Morbidity and Mortality Weekly Report, 69(12), 339-342. http://doi.org/10.15585/mmwr.mm6912e1

Research Office of the Hong Kong Legislative Council Secretariat. (2017). Residential Care Services for the Elderly, 14 March 2017. https://www.legco.gov.hk/research-publications/ english/1617issh22-residential-care-services-for-the-elderly-20170314-e.pdf

Tong, Y., Chen, F., and Su, W. (2019). Living arrangements and older people's labor force participation in Hong Kong, 1986-2016. Social Science $\mathcal{E}$ Medicine, 229, 50-59. https: //doi.org/10.1016/j.socscimed.2018.10.011

Undurraga, E. A., Chowell, G., and Mizumoto, K. (2021). COVID-19 Case fatality risk by age and gender in a high testing setting in Latin America: Chile, March-August 2020. 
Infectious Diseases of Poverty, 10, Article 11. https://doi.org/10.1186/s40249-02000785-1

United Nations, Department of Economic and Social Affairs, Population Division. (2017). Living Arrangements of Older Persons: A Report on an Expanded International Dataset. (ST/ESA/SER.A/407). https://www.un.org/en/development/desa/population/publications/ pdf/ageing/LivingArrangements.pdf

United Nations, Department of Economic and Social Affairs, Population Division. (2019). World Population Prospects: The 2019 Revision. https://population.un.org/wpp/

Wagner, E. H. (2020). The vulnerability of nursing home residents to the Covid-19 pandemic. International Journal of Care Coordination, 23(2-3), 57-60. https://doi.org/10.1177/ 2053434520958860

Wang, X.-Q., Song, G., Yang, Z., Chen, R.-J., Zheng, Y.-L., Hu, H.-Y., Su, X., and Chen, P.-J. (2020). Association between ageing population, median age, life expectancy and mortality in coronavirus disease (COVID-19). Aging, 12(24), 24570-24578. https://doi. org/10.18632/aging.104193

Wong, K., and Yeung, M. (2019). Population ageing trend of Hong Kong. Population, 18, 64.

Wong, L. T. (2018). Tiny affordable housing in Hong Kong. Indoor and Built Environment, 27(9), 1159-1161. https://doi.org/10.1177/1420326X18792159

Woo, J. (2020). COVID-19 and residential care homes in Hong Kong. Journal of Nursing Home Research, 6, 20-21. http://doi.org/10.14283/jnhrs.2020.4

Xinghui, K., Chen, S., Jiangtao, S., and Wu, W. (2020). Online Day Care Keeping Elderly Hongkongers Active During Isolation. South China Morning Post, 23 March 2020. https://www.scmp.com/news/hong-kong/society/article/3076378/ coronavirus-online-day-care-keeping-elderly-hongkongers

Yu, Y., Lau, J. T. F., Lau, M. M. C., Wong, M. C. S., and Chan, P. K. S. (2021). Understanding the prevalence and associated factors of behavioral intention of COVID-19 vaccination under specific scenarios combining effectiveness, safety, and cost in the Hong Kong chinese general population. International Journal of Health Policy and Management. https://doi.org/10.34172/ijhpm.2021.02

Open Access This article is published under the terms of the Creative Commons Attribution 4.0 International License (https://creativecommons.org/licenses/by/4.0/) that allows the sharing, use and adaptation in any medium, provided that the user gives appropriate credit, provides a link to the license, and indicates if changes were made. 